\title{
A Survey on Institute Automation System
}

\author{
Mr.Shubham Shinde ${ }^{1}$, Mr.Sanket Kathwate ${ }^{2}$, Mr.Rohit Chamle ${ }^{3}$, Prof. Nikhita Nerkar ${ }^{4}$ \\ Computer Department, RMDSSOE, Pune, India ${ }^{1,2,3}$ \\ Comp Department, RMDSSOE, Pune, India ${ }^{4}$
}

\begin{abstract}
Managing Attendance and Generating Question papers digitally is one of the important research topics in computer industry. There are automated systems which record the attendance of students and generate question papers for exams. In this paper, we have proposed a Digital Attendance System which will record the attendance of students and generate question papers. The proposed system will help in avoiding proxy attendance, reduce human efforts of paperwork, maintaining the attendance registers and generate reports as per the needs of academics. The question papers generated by the system will help in giving a good learning experience to students and also to get good results.
\end{abstract}

Keywords: Classroom attendance, Question paper, Attendance report, Feedback.

\section{INTRODUCTION}

The main purpose of the Digital attendance system is to record the presence of Student in the classroom. The system will reduce the stress of manual management of attendance and maintenance of records. In this system the teacher will mark attendance using an Android app. It will also generate the Question paper for Students. We are making android application. The data of student and lectures of each class will be stored in the app for recording the attendance. The subject teacher will enter the class and select the class she has entered in the app .The app will then display the names and roll nos of the students of that class. The teacher will then mark the attendance of students on the app just by tapping in front of the name and roll no of student on the screen. The attendance information will then be sent to the database for analysis and a report will be generated. Teachers conduct assessments to know if students have achieved certain learning objectives or not. They generate variety of question papers as per the university's assessment pattern. It is a very time consuming and challenging task for them to make question papers which meet the learning objectives of the course. There are no standardized methods to ensure quality of question paper. Hence there arises a need to have a system which will automatically generate the question papers with teacher's specification within few seconds.

\section{LITERATURE SURVEY}

In this paper [1], A classroom attendance system using face recognition is most important research topic in computer technology. There are automated systems which are used for recording the attendance of a person within the organization, but the limitation is that the attendance is registered only when entering and leaving the work area. In this paper, we proposed the attendance system using surveillance camera which is used to record the attendance of students in a classroom with some time interval in a day. This system is also used to avoid proxy attendance of students. This automation reduces human efforts of paper work, maintaining the attendance registers, generating reports as needs of academics.

In this paper [2], many questions come up when we think about the academic performance of students and the ways and means to ameliorate that. In today's digital era we can use latest technologies to improve student performance and attendance. Class attendance, quizzes and assignments play a key role in academics. In this paper, we have defined a framework for improving class attendance based on GPS and face detection, and new learning environment where students can use devices like enabled devices, iPad, Tab, iPhone, blackberry, laptop etc. for class quizzes and assignments. We proposed an online as well off-line model for quizzes that will run on platform independent applications.

Author says [3], implement the Online College Management System (OCMS) provides a simple interface for maintenance of student information. It can be used by educational institutes or colleges to maintain the records of students easily. The creation and management of accurate, up-to-date information regarding a students' academic career is critically important in the university as well as colleges. Student information system deals with all kind of student details, academic related reports, college details, course details, curriculum, batch details, placement details and other resource related details too. It will also have faculty details, batch execution details, students' details in all aspects, the various academic notifications to the staff and students updated by the college administration. It also 
Vol. 7, Issue 12, December 2018

facilitate us explore all the activities happening in the college, Different reports and Queries can be generated based on vast options related to students, batch, course, faculty, exams, semesters, certification and even for the entire college The placement officer is responsible for updating the placement related information like eligible criteria for a particular company, arriving date for the company which is coming for recruitment, the list of students who are eligible for attending the recruitment process. E-Library (also referred to as digital library) is a special library with a focused collection of digital object.

In this paper author says [4], to implement the frequently generate good question paper which meets learning objectives of the course, we need expert teachers. But there is shortage of experienced teachers in institutions or university. Existing systems lack the flexibility to support all types of tags identified by researchers. Our system is a great aid for teachers in generating question papers automatically from tagged question repository. While the system designed by us stands out in all available systems, there is scope for more enhancements to make it more useful. Depending on the type of assessment required, the system can be made to select particular question types. For example, if user wants assessment for online quiz, it could smartly include all MCQs. Or if user is choosing term test assessment, more objective type and short answer questions must be preferred. Also, users would be delighted to have a feature to present statistics for gaps in user given specifications and system generated specifications.

Author says [5], SIMS (student information management system) developed independently by School of Information Science \& Engineering of Shandong Normal University, this paper introduces database design, specific realization of each function module and key technologies used in the system. In the .NET environment, using ASP.NET technology, Visual C\# and JavaScript as programming language, this system accesses the database of Microsoft SQL Server 2005 with ADO.NET technology, and could be employed by users with high security following the access control mechanism of RBAC(role-based access control) on Web services.

In this paper [6], a wireless fingerprint attendance management system is designed and implemented .This system based biometrics and wireless technique solves the problem of spurious attendance and the trouble of laying the corresponding network. It can make the users' attendances more easily and effectively.

The paper says [7], that must be reliable and fast responded for the industries and company. RFID (Radio Frequency Identification) is one of the reliable and fast means of identifying any material object. Their significant advantage are that they can read wirelessly, contain more information than barcode and more robust in nature and based on non-line-of-sight technology. RFID tags can read in any environmental challenging conditions where other read technology likes barcode or optical card reader useless. In this paper we purposed a secure system that provides information about authorized and unauthorized persons. In this system when card brought near to the RFID module it reads the card information and it compare with the data in the program memory and displays authorized or unauthorized entry. The door opens for authorized entry and marked the attendance corresponding to that code id and save in excel sheet format in SD card and after that display it's all information on the LCD like name and employee code number that link with authorize entry and welcome message with audio greetings by taking their name which is already saved into SD card and for unmatched entry the gate remain closed and alerts the security person through speakers by playing the separate audio file saying entry is unauthorized.

Author says [8], an effective information system needs to support a set of activities, which enable human beings to achieve effectively the objectives of the organization, supported by computer-based information technology. Traditional styles of attendance management include hand-written signatures, card bell, magnetic card, IC card and RF card attendance machines. These styles cannot avoid checking out the attendance slip. This paper summarizes an improvement for manual attendance system during examination using Wireless Student Attendance System. The implementation combines the wireless technology to trace, store and transfer of data to the host computer for report generation and data analysis.

This system offers effectiveness through its functions in capturing data, minimizing time-constraint, and saving effort to write/collect/check attendance slips. The improved student attendance system provides effectiveness and efficiency in administering and managing the attendance procedure; hence minimizing cost and improving productivity thus improving staff development.

\section{OBJECTIVES}

1. Reduce pains of teachers of generating question papers.

2. Save the paper work of managing the attendance.

3. Decrease time required to access and deliver student records.

4. To make the system more secure. 


\section{IV.PROPOSED SYSTEM}

In the Proposed system the teacher will mark the attendance of students using an android application. The attendance data will be gathered and stored in the database and analyzed to generate reports. The data will be stored in database Class wise (Year, Department, Division, Lectures, Names of students, Roll nos, Prn nos). For generation of question papers, questions from the old papers or questions given through the teachers input will be saved in the question bank in the database. New question papers will be generated by applying algorithms to select questions form the question bank stored in the database. So as per the exam point of view the teachers can make a question paper and give it to the students.

\section{SYSTEM ARCHITECTURE}

Following diagram is our system's architecture diagram:

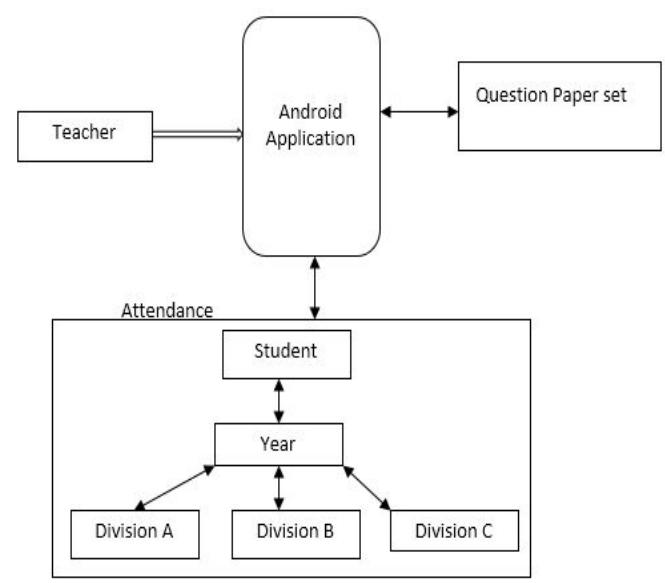

Figure 1: system architecture

In system architecture teacher take Digital attendance using application. And also give a question paper to student as per requirement. In that android application student information is save in year as well as division wise. And in that application question paper are generated. So teacher can select the question and make new question paper and give it the student.

VII. DATA FLOW DIAGRAM

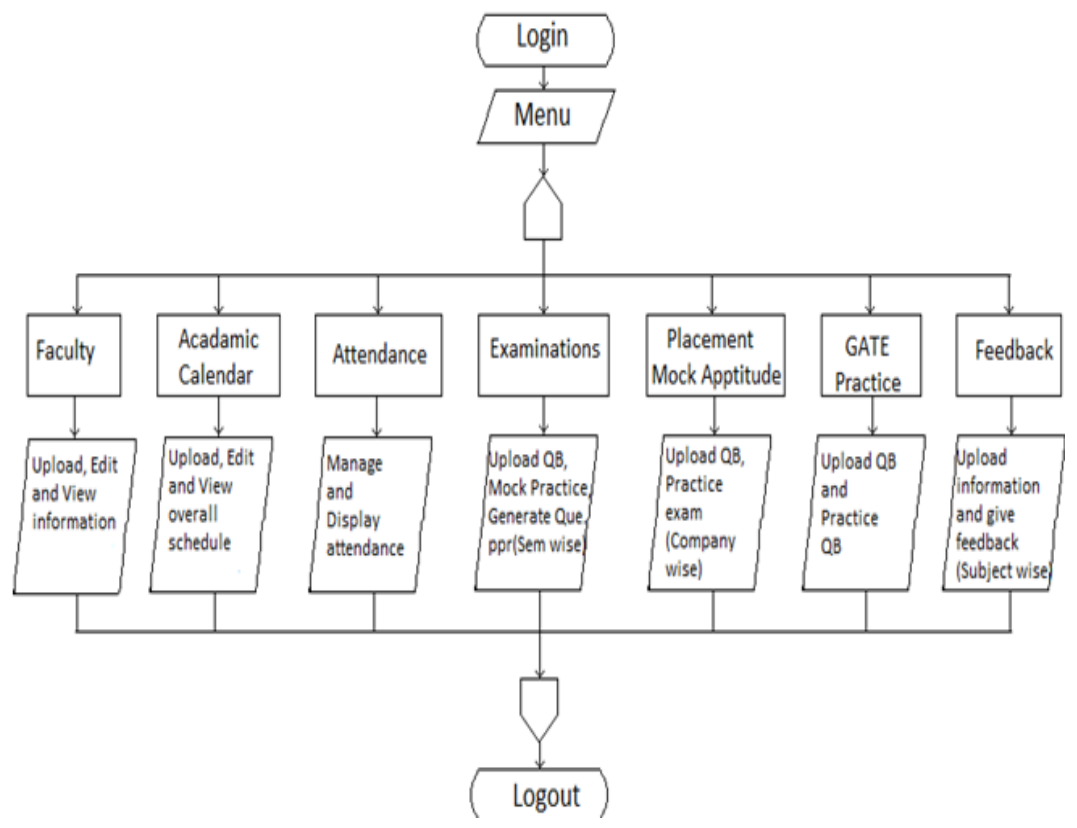

Figure 2: Data flow diagram 


\title{
International Journal of Advanced Research in Computer and Communication Engineering
}

\author{
Vol. 7, Issue 12, December 2018
}

\section{MODULES}

In that some modules are used such as:

1. Digital attendance: Teacher can take a digital attendance using android application. In that the student information is save as per year and Division wise.

2. Question paper generate: In that the year wise question paper are save and in that the teacher can make question paper and give it student. the preamble information available in qp_header table and combine it with question paper table contents to produce question paper in xml format. We preferred xml format as it is supported by all browsers.

3. Feedback: In this module students are able to give feedback to teachers based on their teaching techniques.

\section{CONCLUSION}

This paper assists in automating the existing manual system. This is a paperless work. It reduces the man power. It provides accurate information always. This method will be useful to provide $100 \%$ accurate results. We will use the technique which gives $100 \%$ accuracy with low computational cost. This system will generate attendance reports as needs of academics which make working of organization effective. And help to student in Examination.

\section{REFERRENCES}

[1] Classroom Attendance System Using Surveillance Camera. Ketan N. Mahajan, Nagaraj V. Dharwadkar, international conference on computing, communication and energy systems Jan. 2016

[2] Automatic Attendance and Mobile Learning System in Sensor-Enabled Heterogeneous and Dynamic University Environment.

[3] Online College Management System. Kartiki Datarkar et al, International Journal of Computer Science and Mobile Computing, Vol.5 Issue.4, April- 2016

[4] Automatic Generation of Question Paper from User Entered Specifications using a Semantically Tagged Question Repository. 2016 IEEE 8th International Conference on Technology for Education.

[5] Design and implementation of college Student Information Management System based on Web Services. TANG Yu-fang, ZHANG Yong-sheng, Natural Science Foundation of Shandong Province(Y2008G22), 978-1-4244-3930-0/09 2009 IEEE

[6] The Design of Wireless Fingerprint Attendance System Zhang Yongqiang, LIU Ji Department of Information and Electrical Engineering Hebei University of Engineering Handan, Hebei,P.R.China

[7] Arduino Based Smart RFID Security and Attendance System with Audio Acknowledgement. 